\title{
Cidades visíveis: a esquina da experiência urbana com o jornalismo
}

\author{
Ana Cláudia Peres ${ }^{1}$
}

1 Doutoranda do Programa de Pós-Graduação em Comunicação da Universidade Federal Fluminense (PPGCOM-UFF), na linha de pesquisa Mídia, Cultura e Mediações. anaclaudia.peres@gmail.com 


\section{Resumo}

Palavras-chave

Neste artigo, as cidades devem ser vistas como metáfora e, ao mesmo tempo, lugar de trânsito e passagem, a fim de discutir a linguagem das ruas em narrativas jornalísticas impressas. Ao esboçar uma breve cartografia de textos impressos que, por vezes, são a própria cidade e, em outros casos, o discurso que se constrói sobre ela, localizamos algumas pistas enunciativas que se desenham durante o processo narrativo dos acontecimentos e dão a ver outras possibilidades para o jornalismo em narrativas sobre a cidade que, em vez de aprisionar a experiência urbana, valorizam a potência para o diálogo que há no próprio ato jornalístico.

Jornalismo, narrativa, cidades.

\section{Abstract}

In this article, the cities must be seen as a metaphor and, at the same time, a territory of traffic and passage, in order to discuss the language of the streets in printed journalistic narratives. By sketching a brief cartography of printed texts that are sometimes the city itself and, in other cases, the discourse that is built on it, we located some enunciation cues that are drawn during the narrative process of facts, and allow the interpretation of other possibilities for journalism in narratives about the city that, instead of imprisoning the urban experience, prizes the existing dialogue power in the journalistic act itself.

\section{Keywords}

Journalism, narrative, cities. 
A cidade é o lugar onde todo o possível é convocado.

(Ítalo Calvino)

No mapa das ruas de uma cidade, o que salta aos olhos é uma centena de traços, grafismos aparentemente indecifráveis, um mundo em miniatura. Rio de Janeiro. Santo Cristo. Rua Teixeira Coelho. Avenida Presidente Vargas. Linha Vermelha. Praça Medalha Milagrosa. Favela Baronesa. Caju. Catedral de São Sebastião. Lapa. Largo da Segunda-Feira. Maracanã. Ainda assim, funcionam como pontos de referência que servem ao propósito de orientar. Contudo, "saber orientar-se numa cidade não significa muito" (BENJAMIN, 1997, p. 73), perderse nela é o mais difícil, é algo que exige esforço e requer instrução; algo que se deve aprender a fazer.

À primeira vista, as vias urbanas desalinhadas são como artérias de um corpo sem alma. A cartografia meramente física de um lugar não diz muito acerca dos desejos, dos sonhos, dos afetos, dos problemas, das intenções dos cidadãos desse lugar. Ou seja, não se pode reduzir uma cidade a seu traçado gráfico. Citando Ítalo Calvino, Renato Cordeiro Gomes (2008) nos lembra que, muito mais do que um desenho terminado, "a cidade é o símbolo capaz de exprimir a tensão entre racionalidade geométrica e emaranhado das existências humanas" (p. 24).

Desse modo, pode-se dizer que, para situar-se em uma cidade - e, mais importante, perder-se nela - é necessário construir mapas imaginários que se compõem também de uma memória afetiva e privilegiam o espetáculo das ruas para além do seu ordenamento geográfico. Por levar essa ideia ao extremo, Walter Benjamin acalentava o projeto de fazer um mapa da sua vida que fosse uma espécie de labirinto, onde cada uma das relações importantes que manteve ao longo de sua existência surgisse como uma "entrada" possível (SONTAG, 1992). Em Infância em Berlim por volta de 1900, por exemplo, o autor vai configurando pontos topográficos de um mapa da capital alemã "não como ela se encontra num mapa Pharus, mas tal como se inscreveu na memória de um dos seus habitantes" 
(BOLLE, 2000, p. 332). Nessa ponte construída entre as estruturas da cidade e o mundo dos indivíduos residiria por fim a alma dos lugares.

Imagem cara para o jornalismo, a rua - "a mais igualitária, a mais socialista, a mais niveladora das obras humanas", para falar com João do Rio (2005, p. 48) - ganha status de mito. Para alguns jornalistas, a profissão só se realiza fora das redações, dentro do espaço urbano, nas dobras da cidade. Ricardo Kotscho tem por definição de ofício que "lugar de repórter é na rua". Na opinião do jornalista que prefere ser chamado de repórter, "é lá que as coisas acontecem, a vida se transforma em notícia" (KOTSCHO, 2000, p. 12). Mas a retórica, até certo ponto melancólica, sobre a ida às ruas não pode ser tomada ao pé da letra, sob pena de se transformar em reducionista. Nas palavras do próprio Ricardo Kotscho, ir à rua não significa apenas sair e "gastar a sola do sapato", mas aguçar todos os sentidos para o labirinto das ruas que desenham a cidade e sua cartografia física e simbólica. Ou seja, para além das rotinas da profissão, ir à rua significa perceber a cidade, como alerta ainda Renato Cordeiro Gomes (2008), como "máquina de narrar", onde residem as histórias todas.

\section{A alma das ruas}

Nelson Brissac (1992) alerta para o fato de que, no mundo contemporâneo, a alma dos lugares parece ter se perdido para sempre, graças a habitantes conformados com traçados pré-estabelecidos, reduzidos a locais moldados pelo hábito. Como antídoto a esse estado de desencantamento, o autor sugere ser preciso "redescobrir a paisagem das cidades" (p. 72). Ainda que, na era da velocidade e da técnica, ver a cidade e se deixar seduzir pelas ruas pareça um exercício mais difícil, é preciso ter em mente que é justamente esse o momento em que a metrópole possibilita uma experiência ainda mais rica, com um entrelaçamento de linguagens nunca visto, uma obra aberta em todos os sentidos e direções.

De acordo com Brissac (2003), as cidades são as "paisagens contemporâneas", mas, uma vez que o mundo não se descortina mais como 
nas perspectivas tradicionais, não se pode pretender olhá-lo hoje "como fazia o pintor, com seu cavalete armado no alto de uma colina" (p. 9). É necessário descobrir novas maneiras de enxergar o espetáculo das ruas e construir outras imagens da cidade que passem a compor a paisagem urbana. Trazendo essa leitura para o jornalismo, podemos dizer que, enquanto sujeito que escreve a cidade e, portanto, constrói a cidade, o jornalista não deveria se conformar com o território chapado, aquele que se encaixa na moldura. A narrativa pode ser também um convite à cidade e, sendo assim, deveria comportar a desordem, 0 burburinho, tudo aquilo que transborda e seduz e que constitui, por isso mesmo, o traço mais forte da paisagem urbana.

Aqui, nos parece importante recorrer à figura do flâneur como o primeiro dos paisagistas de uma cidade. Era assim que Walter Benjamin (1997) via aquele que caminha pelas ruas, à deriva, despretensiosamente, mas com atenção suficiente para perceber o charme de uma esquina ou o nome de uma rua, interessado que está em descobrir um desenho urbano feito de uma matéria mais sensível do que paralelepípedos. Para o filósofo alemão, a cidade é a paisagem do flâneur, e ela ganha novos relevos a partir do seu olhar de detetive, de investigador.

João do Rio (2005), flâneur por excelência, dizia que "as ruas têm alma" e que para compreender a "psicologia da rua", é preciso ter o espírito vagabundo e praticar o mais interessante dos esportes: "a arte de flanar", algo que ele definiu como "o vírus da observação ligado ao da vadiagem" (p. 50). O flâneur é tomado aqui de exemplo não com o interesse melancólico de reproduzir as características dessa figura-chave do imaginário do início do século XX. Passear pela metrópole naquela época remetia a uma experiência bem diferente da relação que o cidadão estabelece hoje com a sua cidade, uma vez que agora ela se assemelha mais a um "videoclipe", como nos alerta Canclini (1997), "montagem efervescente de imagens descontínuas" (p. 131).

Recorremos à figura do flâneur porque, a exemplo deste, o jornalista também possui um olhar capaz de redescobrir a paisagem das cidades, a partir 
de suas pistas, seguindo rastros, localizando vestígios, seja nesse ou num outro tempo. Nesses casos, ao modelo de um flâneur - e, por conseguinte, de um paisagista -, cabe ao jornalista, que não se rende à rotina e a agendas oficiais, encontrar um ponto de equilíbrio entre o que está próximo e o longínquo, desenvolver a capacidade de surpreender-se com o trivial, o corriqueiro, ao mesmo tempo que torna familiar aquilo que Ihe é estranho.

\section{A cidade como texto}

Pelo exposto até aqui, podemos avançar na ideia de que cada texto escrito sobre uma cidade é ele próprio uma cidade, feito de ruas, esquinas, pontes, praças, ruínas. Palavras, silêncios, pausas, ruídos, reticências. A narrativa é também a história de si mesma, é o ponto em que "a experiência do sujeito e a experiência da escritura tramam-se" (GOMES, 2008, p. 156). Dessa maneira, pode-se dizer que essa cidade geográfica, cartográfica, vira apenas ponto de partida para cidades feitas de textos, no plural. Isso porque é na tessitura da narrativa que essa cidade se revela para nós, toma forma, ganha sentido.

Se "toda cidade é um texto que eu invento enquanto vivo e reinvento enquanto teço" (RESENDE, 2012, p. 32), podemos imaginar a cidade em seu espaço físico como um labirinto a ser percorrido sem o fio de Ariadne, e que só se desenha de fato à medida que a vivenciamos e, mais tarde, a narramos. Nesse sentido, há que se considerar as muitas cidades que existem em uma. Certeau (1994), que também enxerga a cidade como um texto, parte da premissa de que existe a cidade planejada, dos arquitetos e suas pranchetas, dos peritos e suas disciplinas, mas que só se desenha de fato no momento em que seus homens ordinários trafegam por ela. Para o autor, a cidade do "discurso utópico urbanístico" é uma, mas é o pedestre, o caminhante, o andarilho quem reescreve a cidade, fazendo surgir "uma cidade transumante, ou metafórica, (que) insinuase assim no texto claro da cidade planejada e visível" (p. 172).

Vejamos a narrativa "Cuidado com essa pia...", publicada na Revista Piauí, n. 10, de julho de 2007, que nos ajuda a ler a cidade por um prisma 
menos cartesiano, evidenciando a cidade que extrapola o espaço disciplinado e desordena os sentidos, a partir das histórias de vida dos sujeitos que negociam com ela seus modos de existir.

Manoel Messias tem emprego fixo no calçadão da Princesinha do Mar. Do lado de cá, a ondulação das areias e a beleza das ondas. Do lado de lá, atravessando a avenida, a imponência do Copacabana Palace. Pena que ele não veja nada. Fica tudo lá em cima.

Messias, de 39 anos ("mas pode falar que eu tenho 26 "), é um dos responsáveis pelo banheiro subterrâneo que recebe transeuntes em geral e, em particular, clientes do tradicional Bar Luiz, que mantém um quiosque naquele ponto. (MENAI, 2007).

Assim tem início a narrativa sobre o Projeto Orla, que vai espalhar quiosques pelas praias cariocas, do Leme até a Prainha, no Recreio. O relato é construído de modo a revelar que a cidade fachada do discurso ordenador é uma, mas os modos de vida da cidade real que irrompem na cena acabam por transformar, ainda que involuntariamente, o desenho urbano. É a narrativa que nos mostra isso ao apresentar fragmentos de uma cidade personificados em um trabalhador que vive a metrópole e faz uso dela e sente na pele a interferência provocada por suas transformações, reapropriando-se assim do espaço urbano. É através dele, "Messias", o personagem escolhido como protagonista da narrativa, que o leitor é convocado para conhecer essa outra cidade que emerge dos subterrâneos.

Pelas brechas, a narrativa vai dando pistas de um enredo muito maior, calcado em histórias de vida que acabam por revelar contextos socioeconômicos e políticos. A escolha é pelo singular, pelo detalhe e por tudo aquilo que particulariza uma situação e que, por isso mesmo, acaba sendo revelador das muitas diferenças que convivem em uma cidade.

Os toques futuristas estão por toda a parte, mas, nas pias, atingem a glória: placas de vidro inclinadas a 45 graus do chão descem da altura do umbigo até o rodapé, permitindo, assim, que o cliente fique olhando a água desaparecer lá embaixo, no ralo. O chato é que os mictórios funcionam igualzinho. "Muita gente confunde", diz Messias. "Já cansei de ver marmanjo urinando na pia."

$[\ldots]$ 
As noites mais concorridas, previsivelmente, são as do Ano-Novo. É quando ele faz jus ao título de "salvador das bexigas". Copacabana recebe 3 milhões de pessoas. Não são poucas as que chegam ao banheiro no limite da incontinência. "Só deixo entrar de três em três e divido a fila. Como as mulheres demoram mais, aloco algumas para o masculino". Messias pega no serviço às 4 da tarde e permanece a postos, sem ver a luz do dia, até que o último boêmio do Bar Luiz resolva que já deu, o que nunca acontece antes das 2 ou 3 da manhã. Mora na Praça da Bandeira, na zona norte da cidade, perto do Maracanã. De madrugada, o ônibus não gasta mais de vinte minutos. Solteiro, vive com a tia, numa casa com dois banheiros. "São normais, têm o basicão", diz ele, enquanto separa um kit toalha para um turista havaiano (MENAI, 2007).

O desafio desse relato é, antes de reproduzir o visível, "tornar a cidade visível através dos mecanismos da linguagem" (GOMES, 2008, p. 35). Há uma diferença considerável entre as duas proposições. No primeiro caso, a lógica jornalística pretensiosa de abarcar o mundo desconsidera que "a cidade moderna é um mundo inenarravelmente concentrado, impossível de ser reconstruído, ou representado, senão por fragmentos, colagens e refração" (Ibid., p. 157). É o que se faz na segunda opção, quando a cidade aparece em suas "dobras", no proliferar de pequenas narrativas. Messias, no caso, é apenas mais um no meio da multidão de pessoas da cidade, mas o suficiente para nos dar uma leitura possível dela. É a partir de sua relação com a cidade que temos acesso à pluralidade dos discursos que cabem na metrópole, essa que comporta todos os códigos e que nos chega pela narrativa.

Voltando a Certeau (1994), é o filósofo ainda quem chama a atenção para o fato de que, se no discurso hierarquizante a cidade serve de marco totalizador para estratégias socioeconômicas e políticas, "a vida urbana deixa sempre mais remontar àquilo que o projeto urbanístico dela excluía" (p. 141). Há toda uma rede de outros discursos que não se rendem a essa concepção positivista de cidade e que, não por acaso, corresponde exatamente ao discurso ordenador do jornalismo, considerado epistemologicamente um herdeiro do positivismo. Essa "cidade transumante" elabora a todo instante textos que fazem conhecer subjetividades e marcas próprias, e que não podem passar despercebidos, 
seja do discurso do Estado, do discurso midiático ou do discurso das próprias intervenções urbanas. Para Certeau (1994):

\begin{abstract}
Se é verdade que, por toda a parte se estende e se precisa a rede da vigilância, mais urgente ainda é descobrir como é que uma sociedade inteira não se reduz a ela: que procedimentos populares (também minúsculos e cotidianos) jogam com os mecanismos da disciplina e não se conformam com ela a não ser para alterá-los (p. 41).
\end{abstract}

Em síntese, essa cidade vista como um texto, escrita por seus caminhantes, espaço em que as experiências se revelam como produtoras de sentido (RESENDE, 2012), evoca textos no jornalismo que se diferenciam das narrativas hegemônicas - aquelas tomadas pela técnica e que, em vez de multiplicar as leituras do espaço urbano, apenas reproduzem o discurso ordenador e acabam por reduzir a cidade ao cartão-postal.

\title{
Via de mão dupla
}

Propomos agora o exercício de leitura do jornal ou revista como se fossem eles próprios uma experiência urbana ou uma cidade polifônica onde letreiros, placas, sinais de trânsito, pichações e outros ícones tipicamente urbanos saltem das ruas para as páginas impressas. Investiguemos em que medida o jornal ou revista consegue abrigar essa "escrita da cidade", o texto urbano que pula de suas ruas e, desse modo, é capaz de ampliar as leituras e representações da cidade. Vejamos esta narrativa:

Surpresas de uma cidade - por vezes de uma forma bem silenciosa, misteriosa até, que zomba com a desatenção nossa de cada dia. Um sujeito, que ninguém viu, nem sabe quem é, se homem ou mulher, menino ou o quê, deve ter pego um cavalete (daqui a pouco o leitor há de concordar) e pintou uma folhinha no "verde" do semáforo da avenida Visconde do Rio Branco com a rua Padre Valdevino, quando a primeira encontra a Aguanambi, fechando a bifurcação.

O semáforo é daqueles de chão (daí o cavalete) e a pintura parece (impossível afirmar com precisão) ser feita de tinta spray. Um adesivo simples, na forma da folha da cannabis sativa ajudou a definir a forma que ali ficou, há cerca de três meses. Quase quatro, talvez. Mais que dois, com certeza (LOPES, 2011). 
Publicada originalmente no jornal O Povo, de Fortaleza (CE), a narrativa dá conta de uma intervenção em um semáforo em um dos cruzamentos mais movimentados da cidade. Em matéria que ocupa uma página, investiga o desenho-adesivo que vem chamando a atenção - às vezes nem tanto - de motoristas e pedestres que trafegam pelo local. Num jogo com o leitor, a matéria não sai em busca do autor da intervenção para uma entrevista, tampouco investiga, como é mais comum em matérias desse tipo que ocupam os jornais diários, o significado da 'novidade'. Se se trata de uma intervenção artística, uma subversão às leis do trânsito ou ainda um libelo antirrepressão em tempos de polêmica sobre a descriminalização da maconha, isso vai aparecer no modo como a jornalista escolheu para narrar o acontecimento. Ao fazer do passeio pela cidade uma experiência sensorial, essa narrativa nos ajuda a conhecer o cotidiano de Fortaleza.

A matéria foi veiculada na mesma edição do jornal O Povo que, oito páginas antes, trazia a narrativa "PM é morto com tiro na cabeça" (2011), sobre um assassinato num bairro da periferia. Nesse caso, a matéria se desenrola com parágrafos inteiros de rigorosa apuração técnica, calcada nas fórmulas do jornalismo hegemônico: "De acordo com o major...", "segundo testemunhas...", o que evidencia o jornalismo como uma prática plural que comporta ambas as possibilidades narrativas. As duas matérias dão a ver a cidade. Num caso como no outro, o leitor é conduzido a pistas que, somadas às outras matérias sobre Fortaleza também publicadas naquela edição, ajudam a montar um panorama do território, e funcionam como peças do grande quebra-cabeças que é a cidade.

Mas as estratégias narrativas são diametralmente opostas. A matéria sobre a intervenção no semáforo, desde o título ("Acende e passa"), dá dicas de uma transgressão no modo considerado legítimo de narrar no jornal. Nela, lê-se:

"Era só o que faltava", comentou o motorista de ônibus, avexado com o dito sinal - mais pela pressa que pela curiosidade. Comandando uma linha freguesa daquela via, ele nunca tinha atentado para a mudança. Queria até saber se era como aqueles que tem uma bicicleta desenhada. Era não. 
O Osmanir, que é Alves Ferreira e dono do restaurante na pontinha de quadra que se forma com a junção da Visconde com a Aguanambi, não tinha tanto tempo para conversas na última segunda-feira, pelo começo do expediente. Ele, que mora em cima do estabelecimento, não prestou atenção na marca do semáforo (LOPES, 2011).

Pode-se argumentar, seguindo o senso comum, que a narrativa sobre a morte do policial não permite o deslocamento das fórmulas, enquanto à segunda, de caráter mais leve, seria dado o salvo-conduto de experimentar a linguagem. Pensar assim é enclausurar a narrativa e também a cidade. Não nos interessa aqui qualificar os formatos narrativos. Por ora, fiquemos com a constatação de que há opções no modo de contar uma história, mesmo se a história é a notícia de um conflito urbano. $\mathrm{E}$, nesse sentido, é preciso treinar o olhar para enxergar a cidade como "o lugar enfeitiçado por excelência, feito de facticidade e magias, que devem ser filologicamente interpretadas, na sua brutalidade ou na sua assepsia" (CANEVACCI, 2004, p. 117).

Em meados dos anos 1920, Walter Benjamin começa a elaborar um projeto que mais tarde viria se materializar nos livros Rua de Mão Única, Diário de Moscou, Crônica Berlinense, Infância em Berlim por volta de 1900 e no não concluído Passagens. Em todas essas obras, o objetivo principal do filósofo era "representar a grande cidade contemporânea como espaço de experiência, sensorial e intelectual, da Modernidade" (BOLLE, 2000, p. 272), obras que podem ser lidas como constelação de "retratos urbanos", que revelam a metrópole moderna.

Rua de Mão Única, que tomamos como referencial aqui, trata-se de uma representação da metrópole a partir de uma aglomeração de textos triviais que aparecem diariamente aos seus habitantes na forma de uma placa de trânsito, um outdoor, um anúncio qualquer, cartazes, folhetos, tabuletas. Por outras palavras, um fac-símile do que o cidadão enxerga no meio da rua, a exemplo de "Casa Mobiliada", "Canteiro de Obras", "Madame Ariane, segundo pátio à esquerda", "Posto de gasolina", "Atenção, degraus!". 
Ao exercitar essas narrativas, Benjamin (1997) acaba por revelar a cidade como palco de conflitos socioeconômicos e políticos, mas também um território lúdico, labirinto de invenções que combina multidão incalculável de pessoas com uma profusão ainda maior de palavras. Só a título de ilustração, vejamos o que a tabuleta "Posto de Gasolina", dessas que encontramos em cada esquina na metrópole, acaba por suscitar em Benjamin (1997):

A construção da vida, no momento, está muito mais no poder dos fatos que de convicções. E aliás de fatos tais, como quase nunca e em parte nenhuma se tornaram fundamento de conviç̧ões. Nessas circunstâncias, a verdadeira atividade literária não pode ter a pretensão de desenrolar-se dentro de molduras literárias - isso, pelo contrário, é a expressão usual de sua infertilidade. A atuação literária significativa só pode instituir-se em rigorosa alternância de agir e escrever; tem de cultivar formas modestas - que correspondem melhor a sua influência em comunidades ativas que o pretensioso gesto universal do livro em folhas volantes, brochuras, artigos de jornal e cartazes. Só essa linguagem de prontidão mostra-se atuante à altura do momento. As opiniões, para o aparelho gigante da vida social, são o que é o óleo para as máquinas; ninguém se posta diante de uma turbina e a irriga com óleo de máquina. Borrifa-se um pouco em rebites e juntas ocultos, que é preciso conhecer (p. 11, grifos meus).

O trecho selecionado de Rua de Mão Única, além de exemplificar como a cidade fala por meio de seus textos-ruas, mostra como a cultura cotidiana é valorizada pelo autor que não reconhece a supremacia da atividade literária sobre as demais formas de escrita e até, pelo contrário, valoriza muito mais a comunicação das ruas como se a cidade pudesse, além de tudo, influenciar um estilo narrativo. Da mesma maneira, o jornalismo não deveria ter a pretensão de desenrolar-se dentro de "molduras jornalísticas". Nesse sentido, esta outra narrativa, também publicada nas páginas de $O$ Povo, pertence a um jornalismo que não apenas reage aos fatos, mas que também enxerga o pulsar das ruas, transportando-o para suas páginas impressas:

Sem conversa, sem explicação, um homem (dizem) pintou o asfalto. Reverenciava o amor por alguém. "Te amo". "Te quero". "Te desejo". Quem? Não se sabe. Nem mesmo ele tem identidade definida, e parece - só parece - que foi um cara de bigode, de cabelo grande, na bicicleta. 
Apareceu faz duas semanas - ou seria quase um mês? - com um balde de tinta branca na mão, no início da rua Bento Albuquerque, no bairro Papicu, onde as praças são muitas. Foi lá pela meia-noite. Ou era madrugada, mais ou menos quatro horas da manhã? Bom, o certo é que as frases surgiram da noite para o dia. Quer dizer, tem gente que diz que foi aos poucos [...]

"Essas coisas são de gente bem ousada... O pessoal do prédio comentou. Fica todo mundo querendo saber quem foi. A gente só sabe que não foi para ninguém daqui. Aqui só tem velho!", brinca uma moradora das redondezas que, do alto do seu andar, pode ver que um desconhecido deseja alguém. Tem gente que não se importa com isso. Só de saber que o amor move alguém a ponto de deixar rastros na cidade, já dá pra ficar feliz. "Imagina se esse monte de pichação fosse declaração de amor? Fortaleza ia ficar linda!", comenta Francilda Ratts (FOI TUDO CULPA DO AMOR, 2009).

No caso dessa reportagem sobre uma pichação nas ruas de Fortaleza, mais uma vez, notamos uma subversão das técnicas tradicionais. A narrativa não explica o mundo nem encontra respostas precisas. Não localizamos nesse relato as marcas típicas do discurso autoritário do jornalismo como horário exato, local averiguado ou responsáveis pela ação. Muito pelo contrário. Aqui, o "quem", o "quando" e o "onde" são menos importantes do que o modo "como" o fato é narrado.

Tomando como mote (ou pauta) a investigação de práticas cotidianas que subvertem o espaço das cidades, a narrativa traz o desenho urbano para a página do jornal e tece uma narrativa que lança mão de todas as técnicas jornalísticas (entrevistas, descrição de cena, investigação de um fato), mas vai além delas, numa abordagem mais imaginativa, e nem por isso menos representativa de uma realidade cotidiana. Mais uma vez, a narrativa ressignifica os símbolos da cidade que estão por aí, à deriva, espalhados pelas ruas. Essa "coletânea de textos" que é a própria cidade, quando ocupa as páginas de periódicos, acaba provocando uma relação de intimidade versus estranhamento com ela e, para além, uma espécie de empatia entre emissor e receptor da notícia, um intercâmbio cuja tônica é afetiva.

É preciso estar dentro e fora do espaço urbano - diz Canevacci. "Saltar na cidade" (2004, p. 21). Pensando em termos de narrativa jornalística, essa 
proposição conta muito sobre cultura, entendendo o termo não no seu sentido mais restrito, usado comumente para legitimar o poder, ou seja, usado como ideologia, mas no sentido sinalizado por Stuart Hall de cultura como "práticas vividas" ou "ideologias práticas que capacitam uma sociedade, grupo ou classe a experimentar, definir, interpretar e dar sentido às suas condições de existência" (EAGLETON, 2005, p. 55).

Sob essa perspectiva, a cultura nunca pode ser interpretada como o lugar do consenso. É, pelo contrário, o território do conflito, espaço de disputa, luta contra a uniformidade, como lembra Appadurai (2004), alertando para a capacidade de mediação da narrativa no contexto das grandes transformações políticas, econômicas, sociais, porque passa o mundo a partir das últimas décadas do século $X X$, quando foi tomado de assalto por uma explosão tecnológica de velocidade estonteante. De acordo com Appadurai (Idem), esse mundo em que vivemos, que tem a máquina como personagem fundamental, se caracteriza também por outro protagonista: o novo papel da imaginação na vida social.

Para o pensador indiano, a imaginação ocupa hoje o mesmo peso que o surgimento da imprensa em outras épocas. Imaginação, bom que se diga, não no sentido de fantasia, mas de prática social. A imaginação não seria mais privilégio de uns poucos que lançariam mão disso na arte, por exemplo, mas trabalho mental cotidiano de todos.

\footnotetext{
Imagem, imaginado, imaginário: são tudo termos que nos orientam para algo de fundamental e de novo nos processos culturais globais: a imaginação como prática social (...) já não é simples fuga, já não é passatempo de elites, já não é mera contemplação. A imaginação tornou-se um campo organizado de práticas sociais, uma maneira de trabalhar (tanto no sentido de labor como no de prática culturalmente organizada) e uma forma de negociação entre sedes de ação (indivíduos) e campos de possibilidade globalmente definidos (APPADURAI, 2004, p. 48).
}

Vejamos mais um exemplo de como a cidade é inspiradora e palco para o exercício da diferença, uma "guerra de relatos" (CERTEAU, 1994). Mensagens 
escritas em forma de código nos muros de uma cidade sugerem a matéria "Gritomudonomuro" (ESTEVES, 2012), que se propõe a desvendar os segredos de uma escrita em código que há tempos "insulta" os moradores da zona Sul do Rio de Janeiro. O texto vai abrindo caminho para o leitor, deixando pegadas, construindo um itinerário à medida que se narra, exigindo uma tomada de posição por parte do narrador - e também do leitor - sobre que rumo seguir.

\footnotetext{
Era uma sequência de símbolos, pintados em tinta branca, que ocupava toda a altura do pequeno muro. Estendia-se por mais de 100 metros e tinha quase 400 sinais compridos e estreitos. Vários deles eram repetidos, o que sugeria tratar-se de um alfabeto. As letras tinham ângulos retos e poucas curvas. Algumas lembravam a escrita latina era possível identificar um I, um $X$, um $Y$ espelhado, um $U$ de pontacabeça. Não havia espaço que delimitasse as palavras. Se aquilo fosse mesmo uma mensagem, era incompreensível (Ibid.).
}

Assim tem início a narrativa que acompanha "o embate de dois matemáticos com as confissões cifradas e eróticas que uma artista plástica espalhou pelas ruas do Rio", como diz a chamada da matéria. Apesar de revelado, o conteúdo das mensagens aqui não interessa tanto o que estava escrito. Também não havia novidade do ponto de vista do ineditismo da informação jornalística. Em janeiro de 2011, mais de um ano antes, o jornal O Globo havia feito uma matéria com a autora do código urbano. A diferença aqui está nas escolhas que o narrador faz para descortinar essa cidade.

A opção é por deixar todo o processo à mostra, evidenciar as marcas da sua escrita e dar a ver os mistérios e a pluralidade de uma trama urbana. Como nos diz Barthes (2002), o prazer de uma narrativa é imposto pelo ritmo produzido por aquilo que se lê e pelo que não se lê. "O que eu aprecio, num relato, não é pois diretamente o seu conteúdo, nem mesmo sua estrutura, mas antes as esfoladuras que imponho ao belo envoltório: corro, salto, ergo a cabeça, torno a mergulhar" (Ibid., p. 18).

Aqui, a história é apresentada com o enredo sendo desfiado ponto por ponto: em uns momentos avança, noutros recua, dá piruetas, vai-e-vem na 
informação, lançando mão de artifícios para traduzir em linguagem textual todo o intrincado de símbolos do código, um alfabeto inteiro, criado por uma artista plástica - uma das personagens do enredo que conta ainda com dois matemáticos e uns tantos transeuntes. Trechos de cidade. Fragmentos de linguagem.

Depois de cinco páginas de uma narrativa que não se preocupa em simplificar a cidade para o leitor, o texto culmina com o encontro entre criador e criatura, artista plástica e matemático, mediado então pelo repórter que já existe na cena de forma explícita. Nesse exemplo de como a cidade vai parar nas páginas impressas, a narrativa sela uma impressão - do dicionário: "marca ou sinal que fica (ao imprimir)" - sobre a cidade. Por essa estratégia textual, o repórter e também o leitor viram testemunhas da cena da cidade e do seu desdobramento.

Joana revelou o sentido de sua assinatura, RR é o nome com que é conhecida na 'rua'. Contou como surgiu Raguezo, uma criatura sofrida e solitária - no fundo uma alegoria dela mesma. E o enigmático aposto NHVMIDFOMT reúne as iniciais de "nenhum homem vai me impedir de fazer o meu trabalho".

Orenstein repetiu que achava as inscrições muito bonitas. Contou que cogitava estudar desenho industrial. "Queria ter sido artista", disse. Joana Cezar lembrou o dia em que um bêbado - praticamente saiu lendo seus textos depois de ela Ihe dar algumas dicas. E disse ao matemático: "Se seu olhar fosse completamente livre, talvez você conseguisse entender o alfabeto sem a matemática" (ESTEVES, 2012).

Eis o ponto. A narrativa também enriquece a cidade que, para Cordeiro Gomes, pode se revelar como um "tecido de letras" que o narrador faz e desfaz enquanto escreve (2008, p. 159).

\section{Apontamentos finais}

Se Certeau (1994) tem razão em afirmar que o cotidiano existe não apenas em práticas culturais institucionalizadas, mas inventa-se através de mil maneiras, e se, concordando com Appadurai (2004), a imaginação tem papel essencial no mundo contemporâneo, podemos arriscar que a narrativa é o lugar para exercitar a imaginação e ressignificar o mundo, recuperar o tempo, contar 
da vida, provocando assim uma interação com o Outro. Ao narrar subjetividades, o jornalismo recria modos de vida, oferecendo ao público leitor a possibilidade de imaginar o mundo (e de recriá-lo) a partir do que lhe chega por essas narrativas midiáticas diversificadas e plurais.

Nesse sentido, torna-se imperativo exercitar um olhar transversal para as cidades e as narrativas no jornalismo - considerando uma visão de cidade para além dos aspectos funcionalistas e racionais (GOMES, 2008) e de narrativa como um elemento de ligação entre os vários sujeitos que habitam essa cidade enquanto espaço territorial e simbólico.

Neste artigo, ao esboçar uma breve cartografia de textos impressos que, por vezes, são a própria cidade e, em outros casos, o discurso que se constrói sobre ela, localizamos algumas pistas enunciativas que se desenham durante o processo de narrativização dos fatos e dão a ver outros possíveis para o jornalismo em narrativas jornalísticas sobre a cidade que, em vez de aprisionar a experiência urbana, valorizam a potência para o diálogo que há no próprio ato jornalístico. Isso nos permite afirmar que, se comunicação é desvio e ruído, como nos diz Flusser (2007), a narrativa é mais do que nunca o lugar do encontro, a esquina possível. 


\section{Referências}

APPADURAI, A. Dimensões culturais da globalização: a modernidade sem peias. Lisboa: Teorema, 2004.

BARTHES, R. O prazer do texto. São Paulo: Perspectiva, 2002.

BENJAMIN, W. Obras escolhidas II: rua de mão única. São Paulo: Brasiliense, 1997.

BRISSAC, N. Paisagens urbanas. São Paulo: Editora Senac, 2003.

BOLLE, W. Fisiognomia da metrópole moderna: representação da história em Walter Benjamin. São Paulo: Edusp, 2000.

CALVINO, I. As cidades invisíveis. São Paulo: Companhia das Letras, 1995.

CANCLINI, N. G. Culturas híbridas: estratégias para entrar e sair da modernidade. São Paulo: Edusp, 1997.

CANEVACCI, M. A cidade polifônica: ensaio sobre a antropologia da comunicação urbana. São Paulo: Studio Nobel, 2004.

CERTEAU, M. A invenção do cotidiano 1: artes de fazer. Petrópolis: Vozes, 1994.

EAGLETON, T. A ideia de Cultura. São Paulo: UNESP, 2005.

ESTEVES, B. Gritomudonomuro. Revista Piauí [online], 2012. Disponível em: <http:// revistapiaui.estadao.com.br/materia/gritomudonomuro/>. Acesso em: 26 nov. 2015.

FLUSSER, V. O mundo codificado: por uma filosofia do design e da comunicação. São Paulo: Cosac Naify, 2007.GOMES, R. C. Todas as cidades, a cidade: literatura e experiência urbana. Rio de Janeiro: Rocco, 2008. 
FOI TUDO CULPA DO AMOR. O Povo, Fortaleza, 18 nov. 2009. Caderno Vida \& Arte, p. 1.

PM É MORTO COM TIRO NA CABEÇA. O Povo, Fortaleza, 10 ago. 2011. Editoria Cotidiano, p. 5.

KOTSCHO, R. A prática da reportagem. São Paulo: Ática, 2000.

LOPES, J. Acende e passa. 10 ago. 2011. Disponível em: <http://coletivodar. org/2011/08/acende-e-passa-semaforos-de-fortaleza-aderem-a-marcha-damaconha/>. Acesso em: 26 nov. 2015.

MENAI, T. Cuidado com essa pia... A nova jóia da orla de Copacabana fica abaixo do nível do mar. Revista Piauí [online], 2007. Disponível em: <http://revistapiaui. estadao.com.br/materia/cuidado-com-essa-pia/>. Acesso em: 26 nov. 2015.

RESENDE, F. Cidades, culturas e narrativas: espaços de negociação e produção de sentidos. In: MAIA, J; HELAL, C. (Org.). Comunicação, arte e cultura na cidade do Rio de Janeiro. 1. ed. Rio de Janeiro: Eduerj, 2012. v. 1, p. 1-250.

RIO, J. do. A alma encantadora das ruas. São Paulo: Companhia das Letras, 2005.

SONTAG, S. Prefácio: sob o signo de Saturno. In: BENJAMIN, W. Rua de sentido único e infância em Berlim por volta de 1900. Lisboa: Relógio D’Água, 1992.

submetido em: 15 out. 2014 | aprovado em: 05 dez. 2014 